\title{
Application of spectral and spatial indices for specific class identification in Airborne Prism EXperiment (APEX) imaging spectrometer data for improved land cover classification
}

Kallepalli, Akhil, Kumar, Anil, Khoshelham, Kourosh, James, David

Akhil Kallepalli, Anil Kumar, Kourosh Khoshelham, David B. James, "Application of spectral and spatial indices for specific class identification in Airborne Prism EXperiment (APEX) imaging spectrometer data for improved land cover classification," Proc. SPIE 10005, Earth Resources and Environmental Remote Sensing/GIS Applications VII, $100050 Z$ (18 October 2016); doi: 10.1117/12.2241430

SPIE. Event: SPIE Remote Sensing, 2016, Edinburgh, United Kingdom 


\title{
Application of Spectral and Spatial Indices in Specific Class Identification in Airborne Prism EXperiment (APEX) imaging spectrometer data for improved land cover classification
}

\author{
Akhil Kallepalli ${ }^{\mathrm{a}}$, Anil Kumar ${ }^{\mathrm{b}}$, Kourosh Khoshelhamc ${ }^{\mathrm{c}}$, and David B James ${ }^{\mathrm{a}}$ \\ ${ }^{a}$ Centre for Electronic Warfare, Information and Cyber, Cranfield University, Defence \\ Academy of the United Kingdom, Shrivenham, United Kingdom SN6 8LA \\ ${ }^{\mathrm{b}}$ Photogrammetry and Remote Sensing Department, Indian Institute of Remote Sensing, \\ ISRO, Govt. of India, 4, Kalidas Road, Dehradun- 248001 INDIA \\ ${ }^{\mathrm{c}}$ Department of Infrastructure Engineering, University of Melbourne, Australia
}

\begin{abstract}
Hyperspectral remote sensing's ability to capture spectral information of targets in very narrow bandwidths gives rise to many intrinsic applications. However, the major limiting disadvantage to its applicability is its dimensionality, known as the Hughes Phenomenon. Traditional classification and image processing approaches fail to process data along many contiguous bands due to inadequate training samples. Another challenge of successful classification is to deal with the real world scenario of mixed pixels i.e. presence of more than one class within a single pixel. An attempt has been made to deal with the problems of dimensionality and mixed pixels, with an objective to improve the accuracy of class identification.

In this paper, we discuss the application of indices to cope with the disadvantage of the dimensionality of the Airborne Prism EXperiment (APEX) hyperspectral Open Science Dataset (OSD) and to improve the classification accuracy using the Possibilistic $c$-Means (PCM) algorithm. This was used for the formulation of spectral and spatial indices to describe the information in the dataset in a lesser dimensionality. This reduced dimensionality is used for classification, attempting to improve the accuracy of determination of specific classes. Spectral indices are compiled from the spectral signatures of the target and spatial indices have been defined using texture analysis over defined neighbourhoods. The classification of 20 classes of varying spatial distributions was considered in order to evaluate the applicability of spectral and spatial indices in the extraction of specific class information. The classification of the dataset was performed in two stages; spectral and a combination of spectral and spatial indices individually as input for the PCM classifier. In addition to the reduction of entropy, while considering a spectral-spatial indices approach, an overall classification accuracy of $80.50 \%$ was achieved, against $65 \%$ (spectral indices only) and $59.50 \%$ (optimally determined principal components).
\end{abstract}

Keywords: Hyperspectral Imaging, Sub-pixel Classification, Spectral Indices, Spatial Indices, Dimensionality, Hughes Phenomenon

\section{INTRODUCTION}

Acquisition of spectral information from a target without being in physical contact is referred to as remote sensing. Broadly speaking, spectral information is acquired in two types of 'band' arrangements - multi-spectral and hyperspectral imaging. Multi-spectral imaging is spectral information depicted in the form of broad bands, each covering a range of the electro-magnetic spectrum. Hyperspectral imaging on the other hand produces a spectral definition of the target in many, contiguous bands of narrow or specific wavelengths $[1,2]$. Hyperspectral imaging has an intrinsic diagnostic characteristic (biophysical characteristics of vegetation can be distinguished at each wavelength when spectral information is collected using hyperspectral imaging as shown in Figure 1)

Address all correspondence to

Akhil Kallepalli, E-mail: a.kallepalli@cranfield.ac.uk

Earth Resources and Environmental Remote Sensing/GIS Applications VII, edited by Ulrich Michel, Karsten Schulz, Manfred Ehlers, Konstantinos G. Nikolakopoulos, Daniel Civco, Proc. of SPIE Vol. 10005, $100050 Z$ (C) 2016 SPIE · CCC code: 0277-786X/16/\$18 · doi: 10.1117/12.2241430 
of identifying specific features $[3,4]$ of the target of interest due to the ability of identifying minor changes in spectral reflectance, in comparison to multi-spectral imaging.

Through the advent of imaging spectroscopy, arose the questions of efficiently handling the large amount of data that hyperspectral imaging provides [4]. Although the contiguous bands provide a greater spectral detail of information, hyperspectral imagery brings with it the "curse of dimensionality". Also known as the Hughes Phenomenon [5], the statistical accuracy of class recognition optimises at a subset of bands and subsequently declines due to inadequate training samples [6]. Reduction of computational load and benefits of dimensionality reduction have been widely researched and accepted $[1,3,7]$.

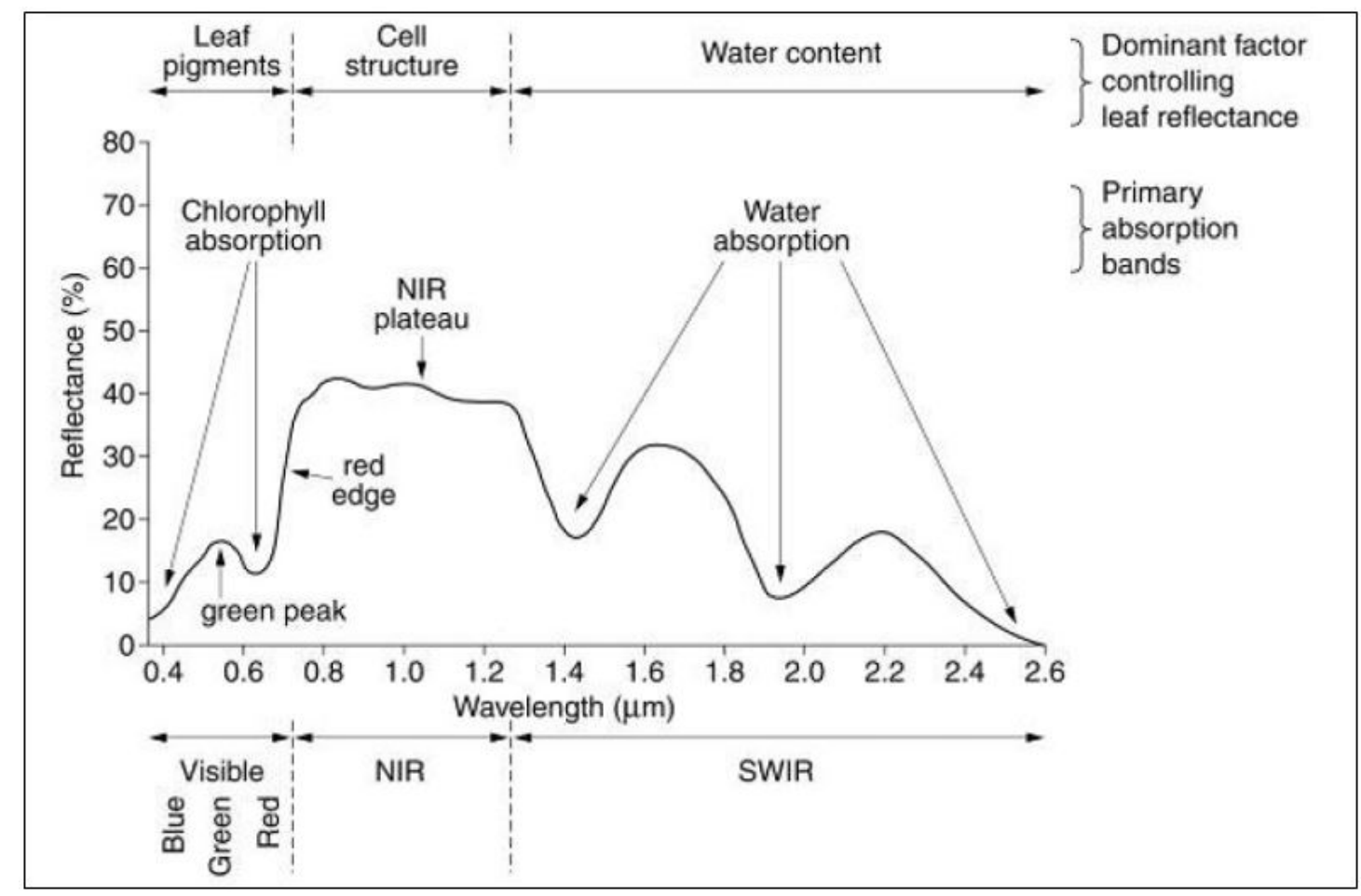

Figure 1. Identifiable aspects of vegetation, when spectral information is acquired in contiguous bands [8].

The current research reports the usage of an input database of spectral and spatial indices for improving the classification accuracy, using Possibilistic $c$-Means (PCM), while intrinsically reducing the dimensionality of the dataset. The Airborne Prism EXperiment (APEX) Open Science Dataset (OSD) was used in this study. To demonstrate the improvement of classification accuracy, a baseline classification accuracy for comparison was established using Principal Component Analysis (PCA) for dimensionality reduction and establishing entropy for statistical quantification of uncertainty [6]. At the outset, the authors would like to mention that the classification approach is targeted at specific class identification and not overall classification accuracy. A detailed literature survey regarding the following topics is available in Kallepalli, A. (2014) [9].

\section{DIMENSIONALITY}

The intrinsic diagnostic qualities of hyperspectral imagery stand strong in multiple applications that require differentiation of targets like vegetation extent and health analysis, biomedical research, etc. This ability, in comparison to multi-spectral imaging, is due to the greater spectral resolution [3] of hyperspectral imaging. However, this spectral information is acquired at the expense of classification accuracy and high computational requirements. Hughes [5] described this phenomenon as a statistical inadequacy of training samples in comparison to number of bands of the dataset. A 'peaking phenomenon' was said to occur with accuracy improving for a subset of bands, and thereby reducing with every added band of information. Although this phenomenon 
was challenged to be an 'apparent' phenomenon by researchers like Van Campenhout [10], the reduction of hyperspectral data's dimensionality is still considered a key step in the pre-processing. In order to avoid the problem of dimensionality, methods like PCA [11,12], Minimum Noise Fraction (MNF) [13], usage of orthogonal subspace projections [7], morphological transformations [14] etc. have been used for information extraction. While methods like PCA employ linear transformations to convert the data into a reduced or "intrinsic dimensionality" [15], such transformations are not universally applicable. Harsanyi and Chang (1994) [7] attempted to simultaneously reduce the dimensionality and classify the dataset by projecting the signals into orthogonal subspace for eliminating the undesired signatures and improving signal-to-noise ratios. Plaza et al., 2005 [14] formulated a sequence of morphological transformations for filtering and classifying high dimensional data.

It is important to note the difference of dimensionality reduction methods generally applied. Feature selection methods refer to algorithms that output a subset of the original dimensionality, while methods that create new features either by transformation or combination of input features are referred to as feature extraction [16]. Besides reducing the computational load of the algorithm, dimensionality reduction greatly improves the classification accuracy as it results in a comparable number of training samples against a subset of bands with the information from the original imagery. However, the disadvantages of methods like PCA are they assume that the dimensionality of the data can be reduced by linear transformations when data could be non-linear in relation, and the initial components are dominated by data that shows greater variance while not (with exceptions) maximising extracted information [11]. These disadvantages have prompted further research into non-linear and/or knowledge-based dimensionality reduction, as is this case in this current research.

\section{PIXEL-BASED SPECTRAL INDICES}

Spectral indices utilise discernible features in the spectral response of the target to distinguish it from the background. The quantification of biophysical variables from remote sensing was explored [17], introducing colour and spectral signatures of features [18-20]. The formulation of spectral indices began with early research into Simple Ratio (SR) [21] of bands. The contrasting spectral response (Figure 1) in infrared (800nm) and red $(675 \mathrm{~nm})$ regions was explored through a ratio of individual pixel values.

One of the most popular indices remains to be Normalised Difference Vegetation Index (NDVI) [22], which is a modified version of SR index. Using a simple ratio of the reflectance values in the infrared and red bands $\left(\left(R_{N I R}-R_{R}\right) /\left(R_{N I R}+R_{R}\right)\right.$ for Landsat 1 data $)$, Rouse et al. [23] applied NDVI for the first time to enhance the vegetation features against the background. This index has found and remains to have numerous applications. Although the delineation of vegetation features is done satisfactorily using NDVI, the correlation between various vegetation parameters and influence of the underlying soil reflectance [24] impacts the results of NDVI analysis. To address these vegetation-specific identification, many indices have been formulated for chlorophyll content [25-27], Leaf Area Index (LAI) [28-30], etc.

Triggered by research into exploring the spectral qualities of vegetation, Huete (1988) [24] attempted to remove the implications of soil substrate by developing the index, Soil Adjusted Vegetation Index (SAVI):

$$
S A V I=\frac{\left(R_{N I R}-R_{R}\right)}{\left(R_{N I R}+R_{R}+L\right)} \times(1+L)
$$

where $L$ defines the prior knowledge of the vegetation density, i.e. low vegetation $(L=1)$, intermediate vegetation cover $(L=0.5)$ and high density vegetation cover $(L=0.25)$. An improvement to SAVI resulted in Modified SAVI index (MSAVI) [31], eliminating the need for prior knowledge of vegetation density cover:

$$
M S A V I=0.5\left(2 R_{N I R}+1-\sqrt{\left(2 R_{N I R}+1\right)^{2}-8\left(R_{N I R}-R_{R e d}\right)}\right)
$$

Elvidge and Chen (1995) [32] investigated the implications of narrow band data, against broad-band data for estimating LAI and green cover. Applying the basic understanding of chlorophyll absorption in the red and reflectance in NIR spectrum [33], previously defined vegetation indices were explored to highlight the importance of narrow band hyperspectral imagery. LAI and canopy chlorophyll density (CCD) were investigated using previously defined indices [34]. 
Chlorophyll Absorption in Reflectance Index (CARI) [35] was improved to Modified Chlorophyll Absorption in Reflectance Index (MCARI) [30] by comparing the reflectance at $0.67 \mu \mathrm{m}$ to $0.55 \mu \mathrm{m}$ and $0.7 \mu \mathrm{m}$ :

$$
M C A R I=\left[\left(R_{0.7}-R_{0.67}\right)-0.2\left(R_{0.7}-R_{0.55}\right)\right] \times \frac{R_{0.7}}{R_{0.67}}
$$

The diagnostic ability of spectral indices and narrow band imaging were further highlighted through improved pigment and chlorophyll estimation $[36,37]$ in open-canopy tree crops [38], viticulture $[39,40]$ physiological characteristics (Physiological Reflectance Index-PRI) [41], carotenoid quantification [42], etc.

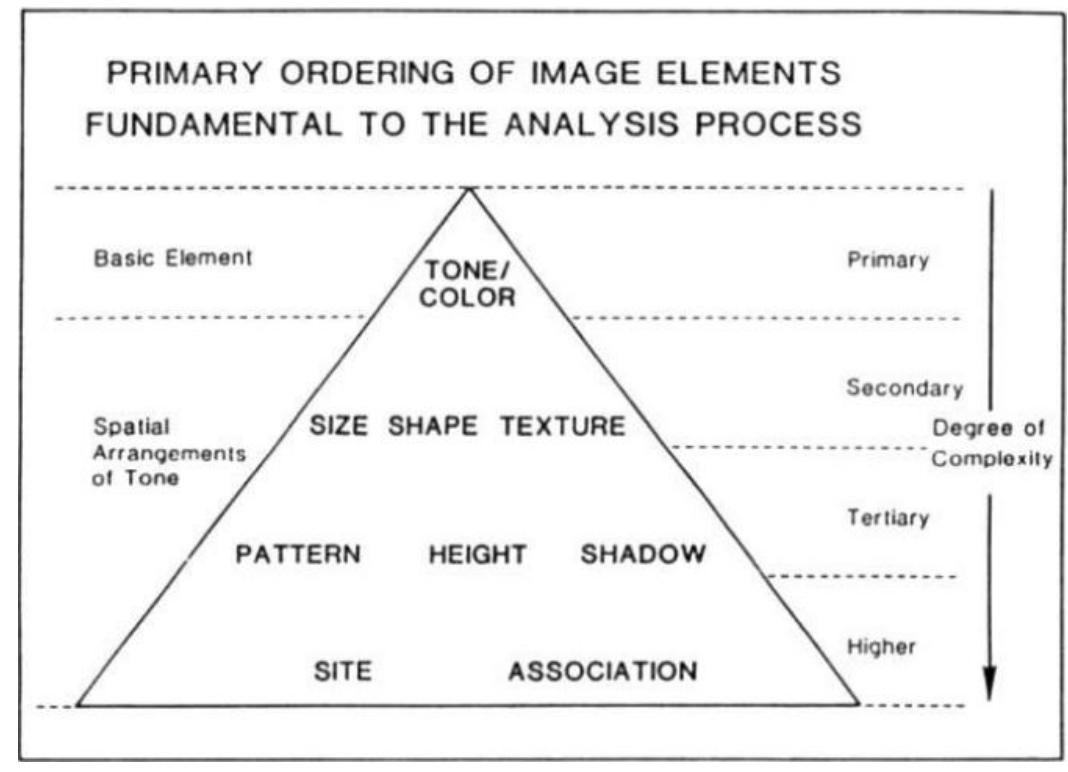

Figure 2. Priority ordering of image elements - Basis of image analysis procedures [19]

The application of spectral indices for enhancing certain features extended beyond vegetation; to classify the built-up area in urban areas using Normalised Difference Built-up Index (NDBI) [43] and outlining the boundary of water bodies using Normalised Difference Water Index (NDWI) using infrared bands $\left(\left(R_{0.86}-R_{1.24}\right) /\left(R_{0.86}+\right.\right.$ $R_{1.24}$ ), where $R$ denotes the reflectance in the respective wavelength) [44].

As hyperspectral imaging provides much greater detail in spectral information, its application and choice of indices' bands depends on the property that is to be enhanced and target of interest. The primary element of image interpretation (Figure 2) remains to be tone/colour, i.e. spectral information.

\section{TEXTURE-BASED SPATIAL INDICES}

Although spatial indices are interpreted in many ways [9], the current research focusses on utilising the spatial variation of pixels and the influence of neighbourhood of pixels on distinction of imaged targets.

The primary pattern elements are considered to be spectral, textural and contextual features [9]. The introduction of the textural features by Haralick et al., 1973 [18] identified the importance and usage of pixel neighbourhood influences. Prior research involved understanding the coarseness of the features, along with the edge definition. Derived textures used angular nearest neighbourhood grey-tone spatial dependence matrices $[18,45]$. Estes et al., 1983 [19] supported the importance of texture in interpretation of imagery (Figure 2). The size, shape and texture of the features, as spatial elements, assists in classification and identification of features. Applications have expanded to interpretation of SAR imagery as well, utilising the grey-tone co-occurrence textural matrices [46]. However, given the implications on the classification of SAR imagery, it could be noted 
that using the most suitable texture analysis elements, instead of all of them collectively, might be a better choice of analysing texture in the work-flow of the image analysis.

Texture analysis have proved to perform as quantitative discriminators along with spatial metrics [45], in order to improve the identification of spatial information from datasets. Through the current work, the authors look to improve the classification accuracy of datasets when using spatial and spectral information together as input to the classifier for identification of specific classes.

\section{METHODS}

Majority of the existing work-flows to classify land use-land cover imagery perform dimensionality reduction first, before employing the classifier for target identification [1,3,7,12,14,47]. A knowledge-based integration of spectral and spatial indices for identifying targets in imagery intrinsically reduces the bands of information given to the classifier.

The dataset and study area have been described in Kallepalli et al., (2014) [6]. Also included in the mentioned literature is the estimation of the baseline classification model (Figure 3) and establishment of entropy being a measure of uncertainty in the classification of the features.

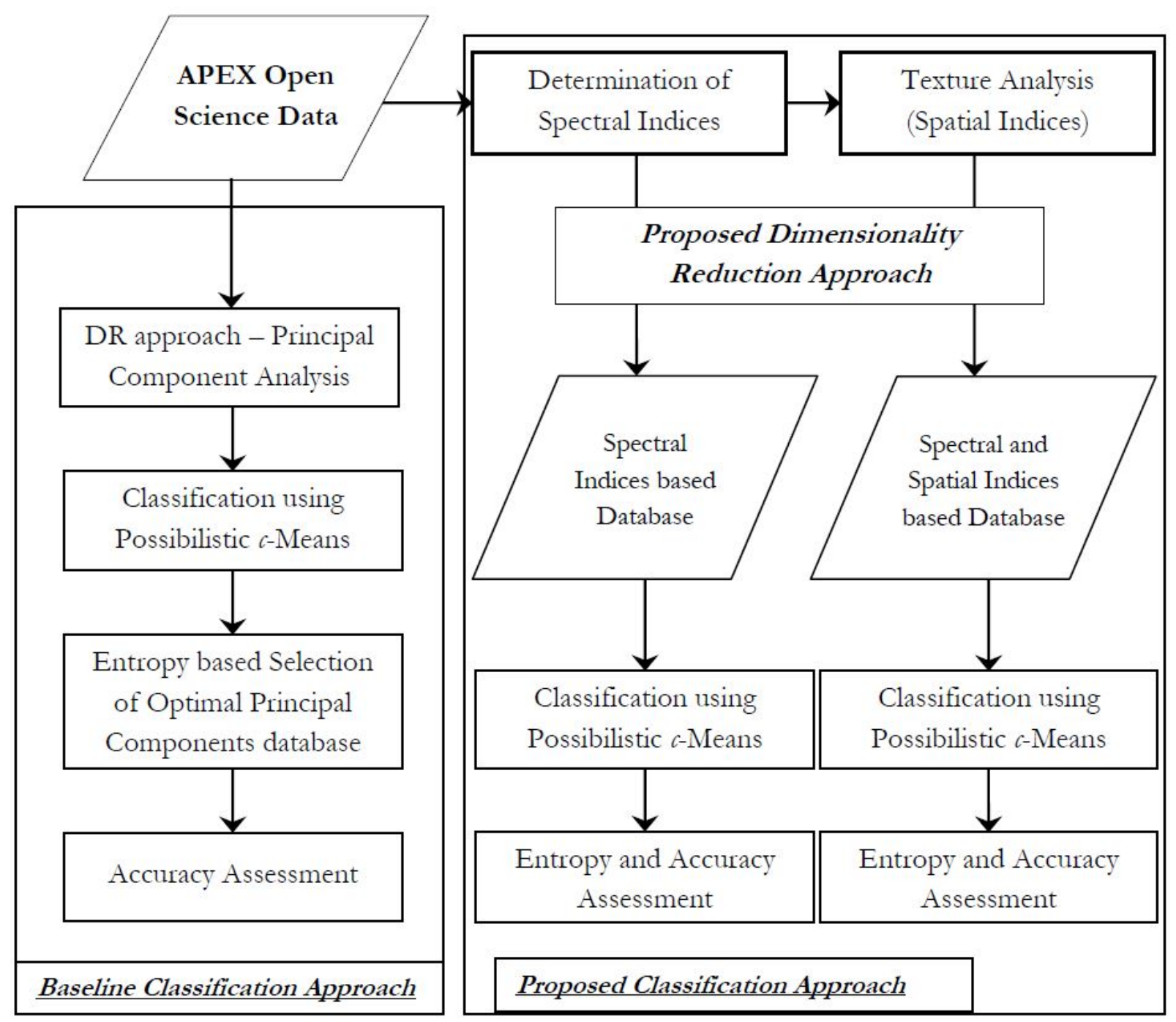

Figure 3. Methodology 
The baseline classification serves as a reference to compare the proposed method of integration of spatial and spectral indices. While using Principal Component Analysis to reduce the dimensionality, the baseline classification is performed using Possibilistic c-means classification (soft classification approach). Subsequent entropy quantification and accuracy assessment provide the comparison metric for the current research.

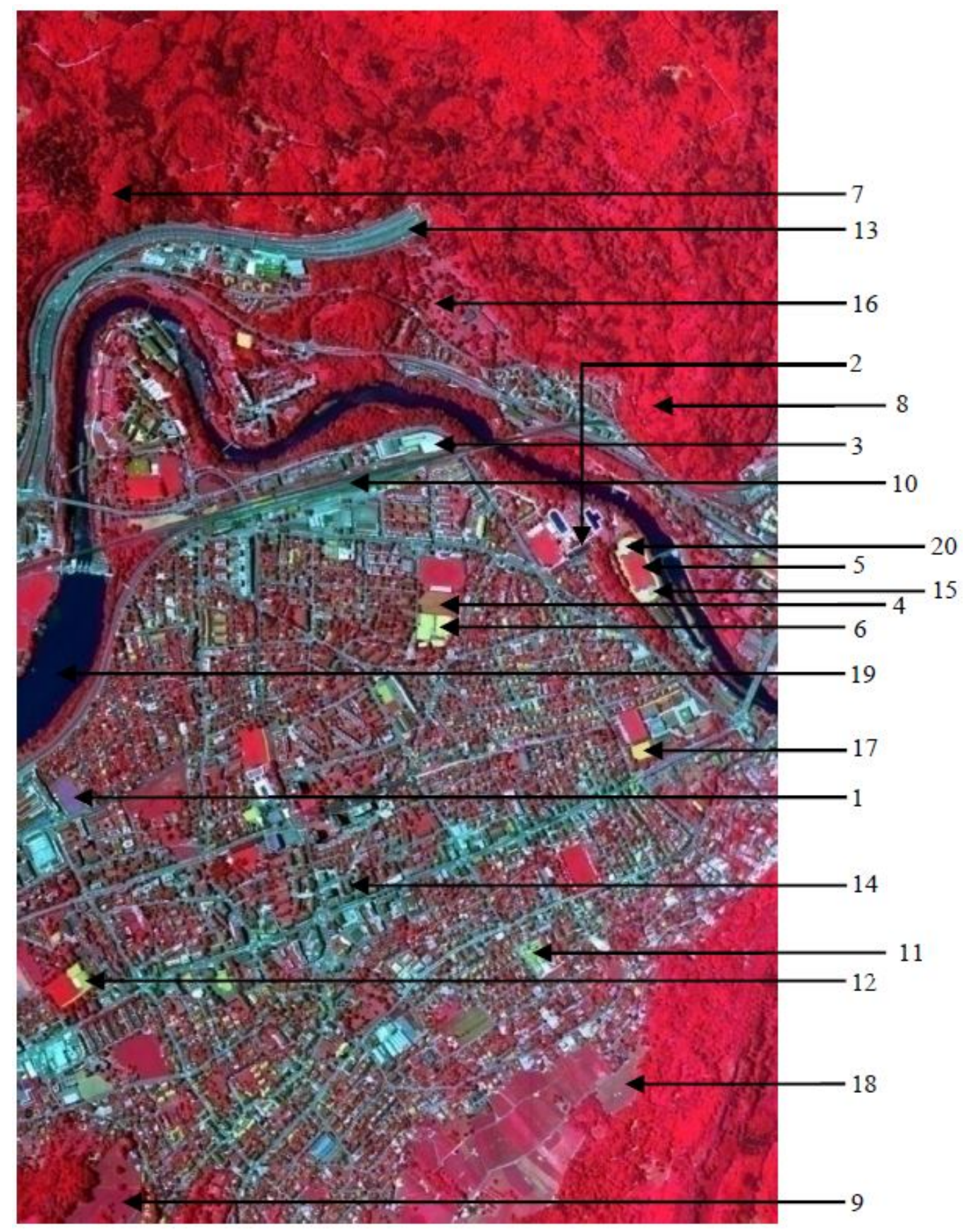

Figure 4. Airborne Prism EXperiment (APEX) Open Science Data (OSD) FCC image of Baden, Switzerland [48], along with the considered classes

The Airborne Prism EXperiment (APEX) Open Science Data (OSD) [49] is freely available [48]. The high spectral resolution (of 285 bands) at $1.8 \mathrm{~m}$ spatial resolution allows spectral investigation of the multiple vegetation 
and urban targets in the study area of Baden, Switzerland (Figure 4). Comparing the spectral characteristics of the targets, indices are drawn up in order to take advantage of the variations of spectral and spatial distribution. The classes investigated are (1) Artificial Turf; (2) Black Roof; (3) Building; (4) Clay Soil; (5) Grass; (6) Lawn Tennis Court; (7) Mixed Coniferous Forest; (8) Mixed Deciduous Forest; (9) Pasture; (10) Railway; (11) Red Roof; (12) Red Synthetic Ground; (13) Road; (14) Roofs; (15) Sand; (16) Stressed Grass; (17) Synthetic Sports Surface; (18) Vineyard; (19) Water and (20) Yellow Tartan. Spectral curves are characterised by 'keys', i.e. bands which, at distinctive positions, assist in identifying the classes.

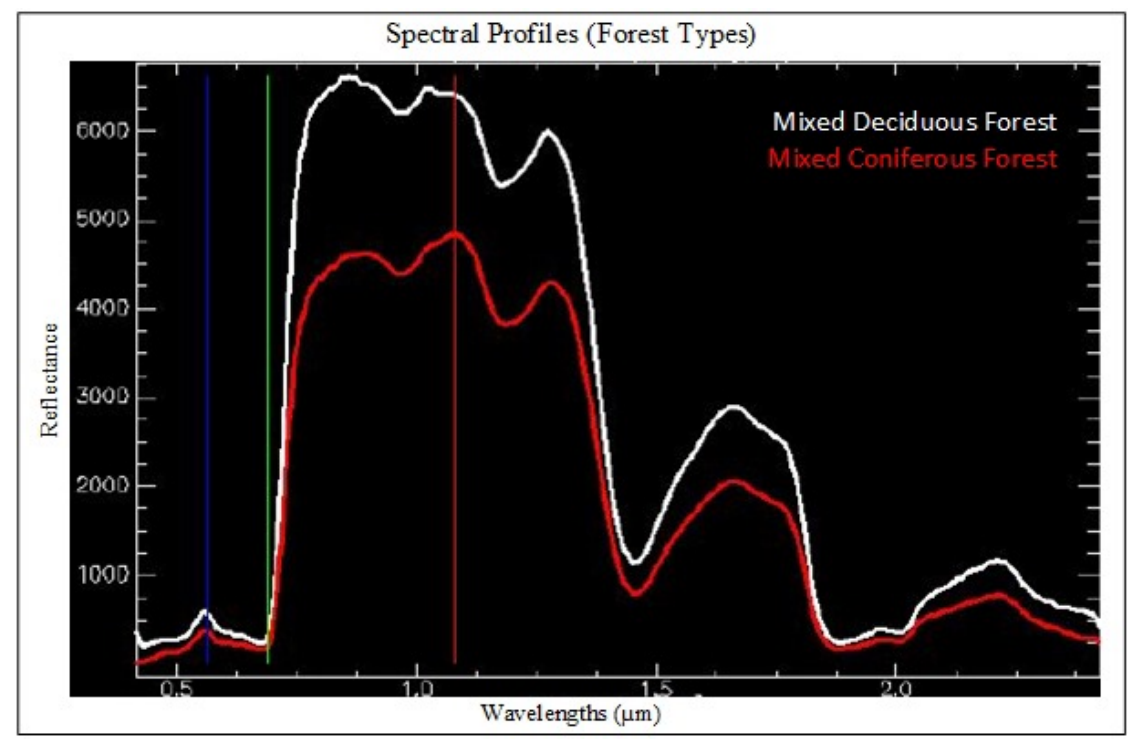

Figure 5. Spectral response of Mixed Deciduous and Mixed Coniferous forests

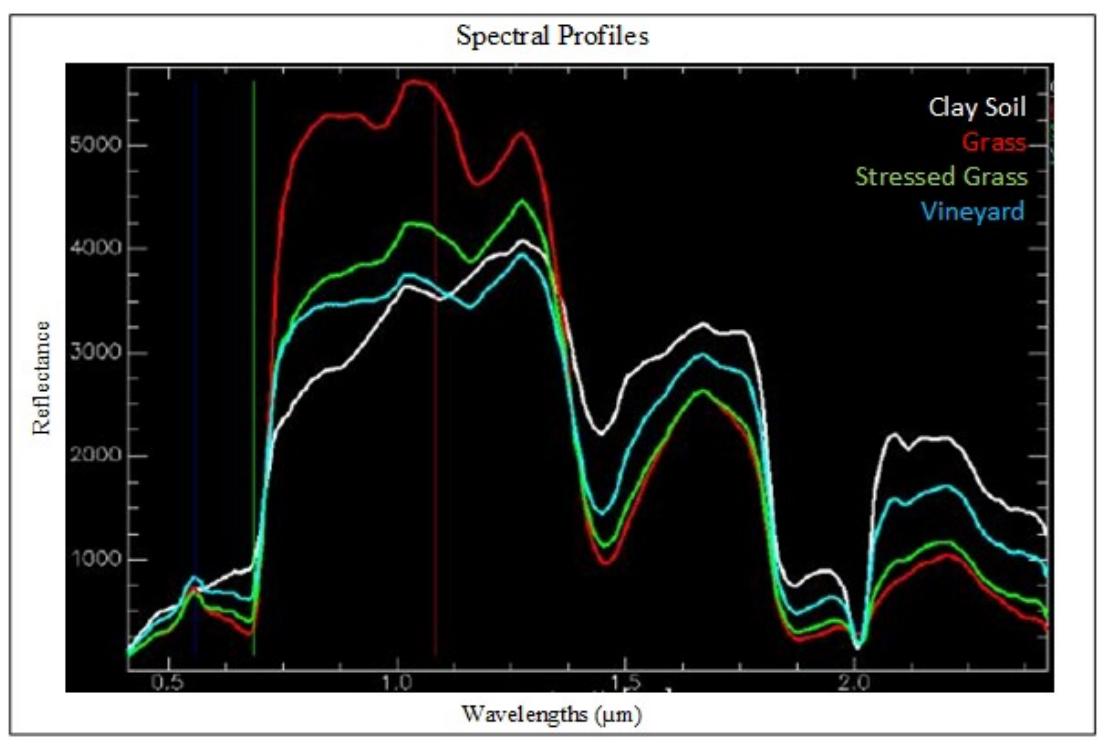

Figure 6. Spectral response of Soil, Grass, Stressed grass and Vineyards

The spectral response of the two types of forests is very similar (Figure 5), varying only in intensity, but not in trend. Attributed to the physical structure of the leaf, deciduous forests provide higher reflectance in comparison to coniferous forests. Similar observations are made when comparing the classes in Figure 6. The most significant 
of observations is the comparison between healthy and stressed grass. Considered to be physically similar, the biological variation of health of grass contributes to the lack of higher reflectance in the case of healthy Grass in the infrared region. The red edge (Figure 1) is known to signify the absorption by leaf pigments and reflectance based on cell structure. Stressed grass's deficiency of leaf pigments contributes to the poorly developed red edge.

Similarly, when comparing the sports surfaces (Figure 7), distinguishable characteristics of Red Sports Surface exist around $0.8 \mu \mathrm{m}$ when the spectral curve (shown in red) shows reflectance while the other two surfaces show absorption.

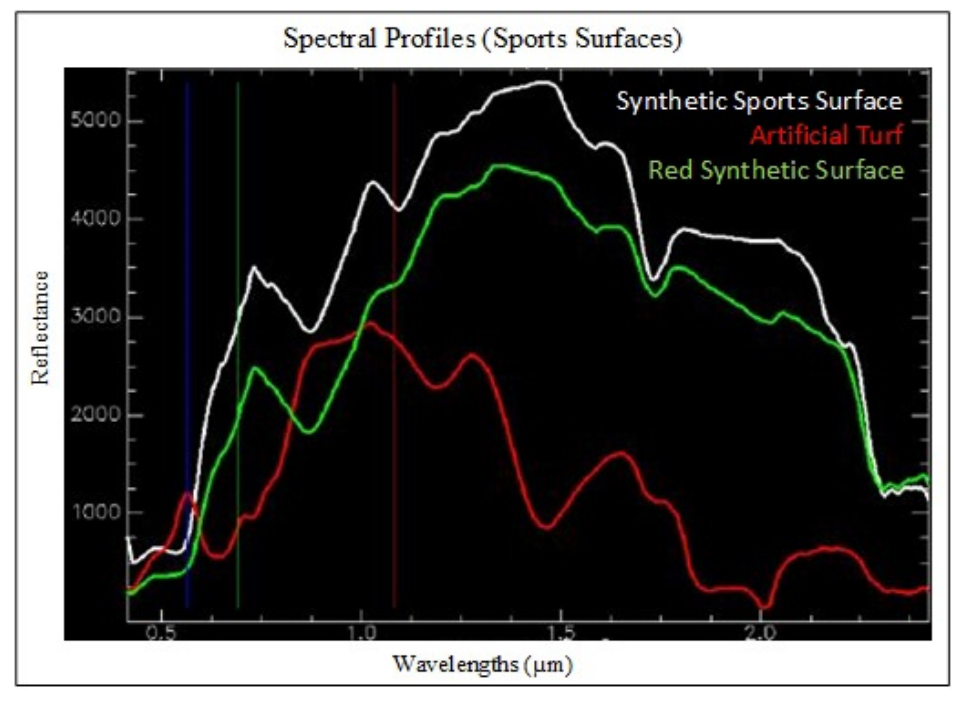

Figure 7. Spectral response of Synthetic, Turf and Red sports surfaces

Utilising the knowledge from the data acquiring agency and SwissTopo portal [50], an interpretation of the image was performed and a training and testing dataset was developed and denoted in Figure 4.

Stressed grass, while following a similar spectral trend, has a much lesser intensity as compared to the Grass (Figure 6). The position of the red edge for both the features is an indicator for variation of health of the vegetation. A shift in the red edge position towards red wavelengths is indicative of reduced absorption due to chlorophyll. The identification of the REP is done by using the first derivative of the spectral curve [51], as a function of $y$ axis, i.e. the reflectance. It provides a peak to identify the specific band number of the red edge. The spectral curve of Stressed grass illustrates a poorly defined red edge (Figure 8) with the first derivative of the spectral curve indicating a shift of red edge position (Figure 9) when compared to well defined red edge for Grass (Figure 10) and the position of the red edge peak at the $64^{\text {th }}$ band (Figure 11).

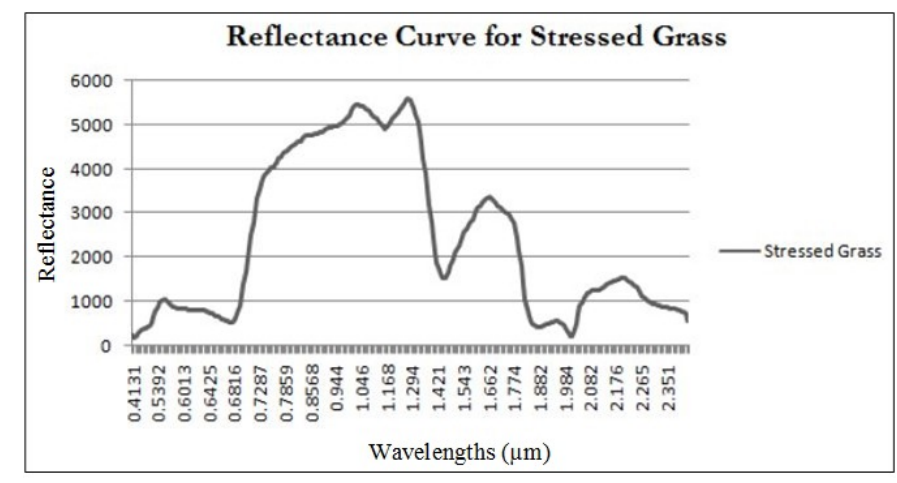

Figure 8. Reflectance curve for Stressed Grass 


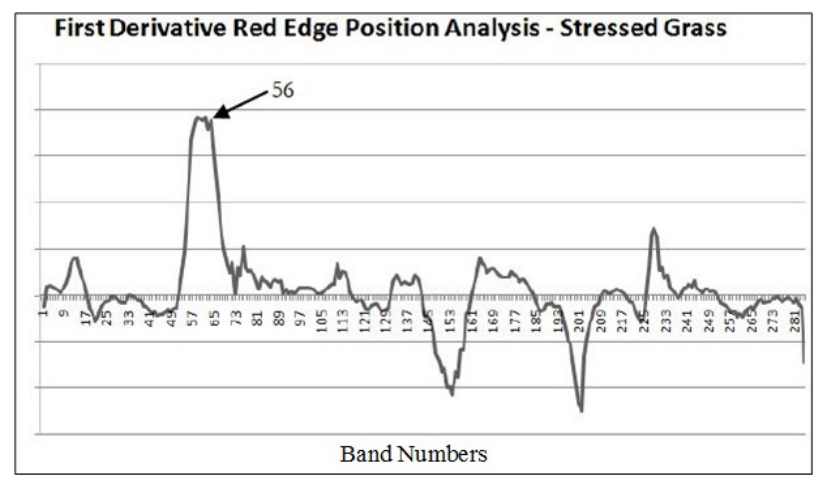

Figure 9. Red Edge Position from the first derivative of the reflectance curve of the Stressed Grass

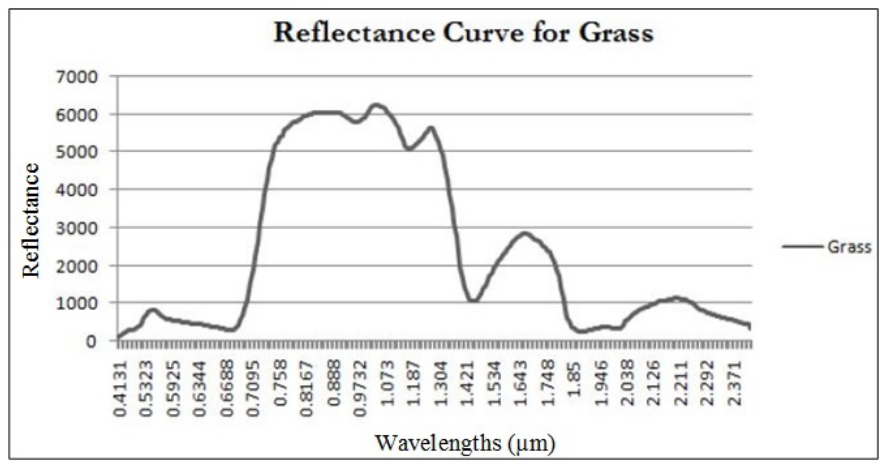

Figure 10. Reflectance curve for Grass

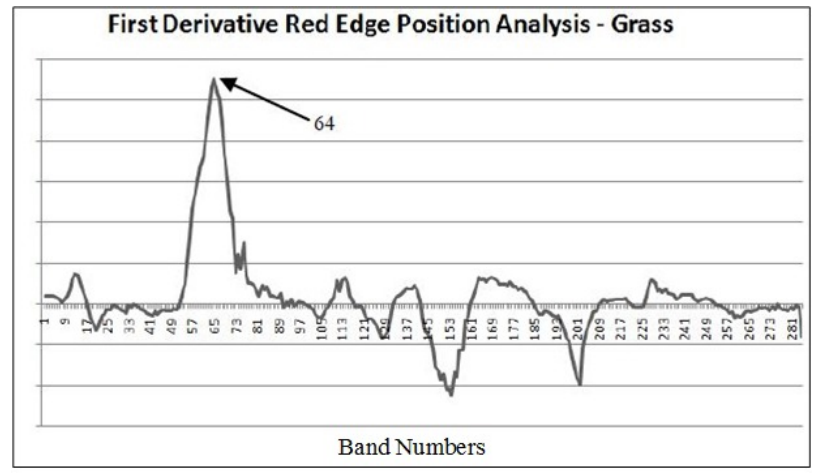

Figure 11. Red Edge Position from the first derivative of the reflectance curve of Grass

\subsection{Classification Approach}

Fuzzy (or soft) classification approaches are chosen for mixed pixel classification and exhaustive definition of object classes, as in this case of using high spectral resolution data. When investigating Fuzzy $c$-means (FCM) and Possibilistic c-means (PCM) for the classification approaches, it was noted that FCM classifier achieved more accuracy but failed when all the classes were not exhaustively defined. Due to the lack of a membership function constraint, PCM is investigated. The membership function, in the case of PCM, of each class is defined using the following constraints [52,53]: 


$$
\begin{gathered}
u_{i j} \in[0,1] \text { for all } i \text { and } j \\
0<\sum_{j=1}^{n} u_{i j} \leq N \text { for all } i \\
\max _{i} u_{i j}>0 \text { for all } j
\end{gathered}
$$

$u_{i j}$ is the membership value of pixel $x_{i}$ belonging to a class $\beta_{i} ; N$ is the number of pixels (or feature points).

The only constraint placed on the usage of the membership value is that it must lie between 0 and 1 . The total of all membership values is not constrained to 1 , as is the case while using the FCM classifier. This allows the classifier to bypass the undefined classes and classify pixels only on the basis of their signature and trained classes [53]. The PCM classifier has been used throughout this research; while defining the baseline classification and application with the spectral and spatial indices databases.

\subsection{Spectral Indices}

After the baseline classification has been established using PCA and Entropy [6], the spectral properties and their significance were investigated. The spectral investigation of the classes begins with identification of 'keys' or specific bands that allow the classifier to distinguish between the targets. These keys are contrasting spectral behaviour of absorption and reflection (troughs and peaks) in the spectral curve. A similar comparison of spectral properties was done for all the identified classes. Illustrated in Table 1 are the relevant properties and their respective wavelength regions for the vegetation features. Note that simultaneous reduction of dimensionality (feature selection, in this case) is knowledge-based, i.e. utilising the spectral information and comparison for input to the classifier.

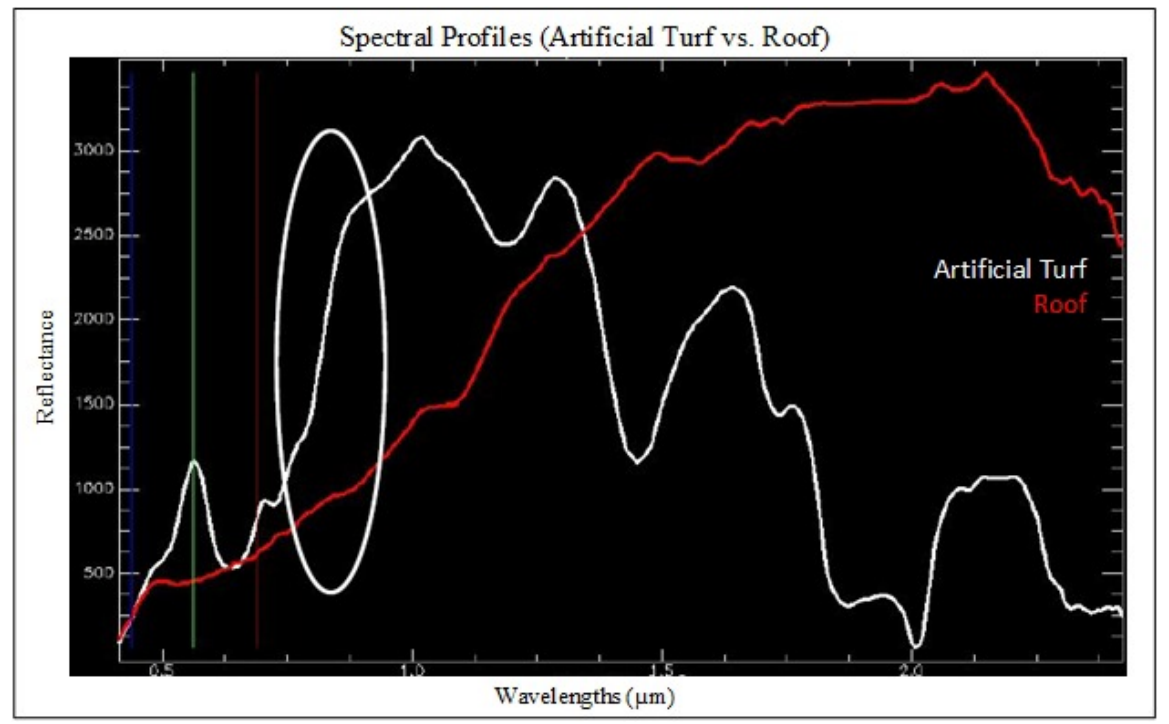

Figure 12. Spectral Curve comparison of Artificial Turfs and Roofs

After extensive spectral investigation, the identified spectral indices and band combinations were determined (Table 2). However, it is important to note that every index does not uniquely identify a specific class. One such example is discussed while comparing the spectral curves of Artificial Turfs and Roofs (Figure 12), the circled region indicative of similar spectral behaviour. The keys identified to classify Artificial Turf class (Table 2) are due the increase in the reflectance. However, in this region, a similar increase is seen for the Roofs class as well, resulting in the index highlighting both classes. A comparison amongst all the 20 classes in the study identifies such conflicts amongst classes (Table 3). 
Table 1. Wavelength and Physical Significance in Vegetation (54-56)

\begin{tabular}{|c|c|c|}
\hline $\begin{array}{l}\text { Wavelength } \\
\text { Portion Name }\end{array}$ & $\begin{array}{l}\text { Wavelength } \\
\text { (ג) in } \mu \mathrm{m}\end{array}$ & Band Description and Significance \\
\hline Blue & 0.49 & $\begin{array}{l}\text { Sensitive to loss of chlorophyll, browning, ripening senescing and } \\
\text { soil background effects. Also sensitive to Carotenoid pigments }\end{array}$ \\
\hline Green 1 & 0.52 & $\begin{array}{l}\text { Maximum "positive change in reflectance per unit variation in } \\
\text { wavelength" of visible spectrum is seen around this green } \\
\text { wavelength and is sensitive to pigment content. }\end{array}$ \\
\hline Green 2 & 0.55 & $\begin{array}{l}\text { Green peak in the visible spectrum; strongly related to chlorophyll } \\
\text { content }\end{array}$ \\
\hline Green 3 & 0.575 & $\begin{array}{l}\text { Maximum "negative change in reflectance per unit variation in } \\
\text { wavelength" of visible spectrum is seen around this green } \\
\text { wavelength and is sensitive to pigment content. }\end{array}$ \\
\hline Red 1 & 0.66 & Chlorophyll absorption pre-maxima (reflectance minima - 1) \\
\hline Red 2 & 0.675 & $\begin{array}{l}\text { Chlorophyll absorption maxima. Greatest soil - crop contrast seen at } \\
\text { this wavelength. }\end{array}$ \\
\hline Red edge - 1 & 0.7 & $\begin{array}{l}\text { Chlorophyll absorption post-maxima (reflectance minima } 2 \text { ). This } \\
\text { point marks the change of maximum red-absorption to dramatic } \\
\text { increase in red reflectance along the red edge. This has been found } \\
\text { to be sensitive to stress levels in vegetation. }\end{array}$ \\
\hline Red edge -2 & 0.72 & $\begin{array}{l}\text { Critical point on the red edge where the "maximum change of slope } \\
\text { reflectance spectra per unit change in wavelength" occurs. Sensitive } \\
\text { to temporal changes in crop growth, stress, etc. }\end{array}$ \\
\hline NIR & 0.845 & Centre of the "NIR shoulder". Strongly correlated to chlorophyll. \\
\hline NIR peak - 1 & 0.905 & $\begin{array}{l}\text { Peak of the NIR spectrum. Sensitive to stress or growth stages of } \\
\text { some crops, where there is significant change in reflectance along the } \\
\text { NIR shoulder. Useful for calculating crop moisture sensitive index. }\end{array}$ \\
\hline NIR peak -2 & 0.920 & Peak of the NIR spectrum. \\
\hline $\begin{array}{l}\text { NIR - Moisture } \\
\text { Sensitive }\end{array}$ & 0.975 & $\begin{array}{l}\text { Centre of moisture sensitive portion of NIR. Various measures of } \\
\text { plant moisture can be made from this wavelength's reflectance. }\end{array}$ \\
\hline
\end{tabular}


Table 2. Spectral indices database chosen for classification input. Band numbers correspond to APEX OSD data

\begin{tabular}{|c|c|c|}
\hline Object Class & $\begin{array}{c}\text { Index } \\
\text { Formulated/Applied }\end{array}$ & APEX Band Combination \\
\hline Artificial Turf & Band Ratio & $95,76(0.8752 \mu m, 0.7716 \mu m)$ \\
\hline Black Roof & Band Ratio & $160,149(1.45 \mu m, 1.343 \mu \mathrm{m})$ \\
\hline Buildings & NDBI & $160,145(1.45 \mu m, 1.304 \mu m)$ \\
\hline Clay Soil & Band Ratio & $236,225(2.09 \mu \mathrm{m}, 2.007 \mu \mathrm{m})$ \\
\hline $\begin{array}{l}\text { Mixed Coniferous } \\
\text { Forest }\end{array}$ & Band Ratio & $85,53(0.8167 \mu m, 0.6816 \mu m)$ \\
\hline $\begin{array}{l}\text { Mixed Deciduous } \\
\text { Forest }\end{array}$ & MTVI1 & $81,17,52(0.7958 \mu \mathrm{m}, 0.5567 \mu \mathrm{m}, 0.6784 \mu \mathrm{m})$ \\
\hline Red Synthetic Ground & Band Ratio & 197, $192(1.782 \mu \mathrm{m}, 1.74 \mu \mathrm{m})$ \\
\hline Stressed Grass & Band Ratio & $234,226(2.074 \mu \mathrm{m}, 2.015 \mu \mathrm{m})$ \\
\hline Vineyard & $\begin{array}{l}\text { Modified NDVI (devised } \\
\text { from spectral curve behavior } \\
\text { in SWIR) }\end{array}$ & $236,225(2.09 \mu m, 2.007 \mu m)$ \\
\hline Water & NDWI & $183,146(1.662 \mu m, 1.314 \mu m)$ \\
\hline Roof & Band Ratio & $142,122(1.275 \mu \mathrm{m}, 1.082 \mu \mathrm{m})$ \\
\hline Basic Vegetation Index & MSAVI & $85,53(0.8167 \mu m, 0.6816 \mu m)$ \\
\hline
\end{tabular}

Table 3. Conflicting classes from identified spectral keys

\begin{tabular}{|l|l|}
\hline Object Class Specific Index & Additional Class Identified through Index \\
\hline Artificial Turf & Roof \\
\hline Black Roof & Water \\
\hline Buildings & Multiple Classes \\
\hline Clay Soil & Artificial Turf, Vineyards \\
\hline Mixed Coniferous Forest & - \\
\hline Mixed Deciduous Forest & Grass \\
\hline Red Synthetic Ground & Multiple Classes \\
\hline Stressed Grass & Clay Soil, Vineyard \\
\hline Vineyard & Clay Soil, Stressed Grass \\
\hline Water & - \\
\hline Roof & - \\
\hline Basic Vegetation Index & All vegetation in the study area \\
\hline
\end{tabular}




\subsection{Spatial Indices from Texture Analysis}

The spectral characteristics of high resolution APEX data have been investigated and class specific information has been obtained through feature selection (key/band identification) and extraction (spectral indices). When dealing with classes that have similar spectral behaviour (like forests and grass), spatial distribution could be a distinguishing factor, as spectral indices will identify both classes. Texture analysis (neighbourhood distribution) has been considered in this literature for the purpose of exploiting the spatial information of the classes.

Haralick et al., 1973 [18] provides a detailed explanation of the Gray-Level Co-occurrence Matrix (GLCM) texture analysis. The method employed involves a selection of a neighbourhood of pixels and assessing the variation of gray-level to identify the most appropriate textural feature. The analysis is performed on the spectral indices output, in order to distinguish between spectrally similar targets. The utilised texture measures are:

$$
\begin{gathered}
\text { Mean }\left(\mu_{i}\right)=\sum_{i, j=0}^{N-1} i\left(P_{i, j}\right) ; \operatorname{Mean}\left(\mu_{j}\right)=\sum_{i, j=0}^{N-1} j\left(P_{i, j}\right) \\
\text { Entropy }=\sum_{i, j=0}^{N-1} P_{i, j}\left(-\ln P_{i, j}\right) \\
\text { Second Moment }=\sum_{i, j=0}^{N-1}\left(P_{i, j}\right)^{2}
\end{gathered}
$$

where $P_{i, j}$ is the $(i, j)^{t h}$ entry in the gray tone spatial dependence matrix; $N$ is the number of gray levels in the quantised image.

Texture analysis is performed on the spectral indices, in order to improve the input database to the classifier. Five spatial indices (Table 4) were added to the spectral indices database to improve the classification accuracy.

Table 4. Selected texture measures (spatial indices) for input to the classifier

\begin{tabular}{|l|c|c|}
\hline Source Spectral Index & Texture & Window Size (Neighborhood) \\
\hline Black Roof & Entropy & $3 \times 3$ window \\
\hline Clay Soil & Mean & $3 \times 3$ window \\
\hline Mixed Coniferous Forest & Second Moment & $3 \times 3$ window \\
\hline MSAVI Vegetation Index & Second Moment & $5 \times 5$ window \\
\hline Roof & Mean & $3 \times 3$ window \\
\hline
\end{tabular}

Second moment generates high results when there exist a few pixels of high magnitude in the neighbourhood window. This texture is applicable to vegetation classes which are highly distributed classes. Entropy generates high output values when measured on neighbourhoods that have a continuous and consistent pixel values. The texture measure derives the desired output when applied to features like Black Roof, which have a consistent distribution of pixel values. The mean distribution of pixel values highlights pixels of high value and increases the separability of classes like Roof and Clay Soil classes. The spectral indices input database, followed by the combined spectral and spatial indices database was evaluated for classification accuracy with the PCM classifier and the results were compared for identifying the applicability of the method. The primary objective is to understand the implications of using the spectral and spatial information for the classification of the dataset, understood after entropy analysis and accuracy assessment (after defuzzification [6]). The accuracy assessment includes: 
1. User's Accuracy (UA) which is the reliability or probability that a pixel class on the image represents the same on the ground.

2. Producer's Accuracy (PA) which represents how well a certain area has has been classified

3. Overall Accuracy (OA) which represents the number of pixels correctly classified when compared with ground truth and knowledge information.

\section{RESULTS}

The results were analysed in combinations of spectral and spatial indices. The available spectral and spatial input bands are 12 and 5 respectively. The presentation of results would be in the order of baseline classification, consideration of spectral indices (only), followed by combination of texture features added to the input database. Entropy measures were not calculated for classes that were not identified using PCM, and therefore depicted in red in the Results tables.

Table 5. Principal Components and Spectral Indices input database - Entropy and Accuracy Assessment Comparison

\begin{tabular}{|c|c|c|c|c|c|c|c|}
\hline \multirow[t]{2}{*}{$\begin{array}{l}\text { Class } \\
\text { No. }\end{array}$} & \multirow[t]{2}{*}{ Class } & \multicolumn{3}{|c|}{$\begin{array}{c}\text { PC Input Database (7 } \\
\text { features) }\end{array}$} & \multicolumn{3}{|c|}{$\begin{array}{c}\text { Indices Input Database } \\
\text { (12 features) }\end{array}$} \\
\hline & & Entropy & $\mathrm{UA}$ & PA & Entropy & $\mathrm{UA}$ & PA \\
\hline 1 & Artificial Turf & & 20 & 100 & 1.94 & 100 & 100 \\
\hline 2 & Black Roof & & 62.5 & $\begin{array}{c}83.3 \\
4\end{array}$ & & 55.56 & 100 \\
\hline 3 & Building & 1.35 & 100 & 50 & & 100 & 42.86 \\
\hline 4 & Clay Soil & 1.334 & 88.89 & 80 & 1.45 & 90 & 100 \\
\hline 5 & Grass & & 40 & $\begin{array}{c}44.4 \\
5\end{array}$ & & 40 & 57.14 \\
\hline 6 & Lawn Tennis Court & 1.26 & 70 & 100 & & 40 & 100 \\
\hline 7 & $\begin{array}{l}\text { Mixed Coniferous } \\
\text { Forest }\end{array}$ & 1.3 & 60 & 40 & 1.62 & 80 & 57.14 \\
\hline 8 & $\begin{array}{l}\text { Mixed Deciduous } \\
\text { Forest }\end{array}$ & & 80 & $\begin{array}{c}29.6 \\
3\end{array}$ & 1.6 & 90 & 50 \\
\hline 9 & Pasture & & 30 & 100 & 1.46 & 55.56 & 100 \\
\hline 10 & Railway & & 28.57 & 100 & & 30 & 50 \\
\hline 11 & Red Roof & 1.1 & 100 & 25 & & 66.67 & 54.55 \\
\hline 12 & Red Synthetic Ground & 1.15 & 60 & $\begin{array}{c}85.7 \\
1\end{array}$ & & 60 & 100 \\
\hline 13 & Road & 0.86 & 90 & $\begin{array}{c}47.3 \\
7\end{array}$ & & 70 & 23.34 \\
\hline 14 & Roof & & 40 & 50 & 0.68 & 100 & 66.67 \\
\hline 15 & Sand & 1.23 & 50 & 100 & & 10 & 100 \\
\hline 16 & Stressed Grass & & 40 & 40 & 1.49 & 70 & 70 \\
\hline 17 & $\begin{array}{l}\text { Synthetic Sports } \\
\text { Surface }\end{array}$ & & 100 & 100 & & 44.45 & 100 \\
\hline 18 & Vineyard & 1.07 & 30 & 50 & 1.49 & 66.67 & 75 \\
\hline 19 & Water & & 100 & 90.9 & 2.06 & 100 & 90.91 \\
\hline \multirow[t]{2}{*}{20} & Yellow Tartan & & 33.34 & 100 & 0.6 & 30 & 100 \\
\hline & $\begin{array}{l}\text { Overall } \\
\text { Classification } \\
\text { Accuracy }\end{array}$ & \multicolumn{3}{|c|}{$59.50 \%$} & \multicolumn{3}{|c|}{$65 \%$} \\
\hline
\end{tabular}


The first input to the classifier are the principal components from PCA. The appropriate number of principal components are determined from entropy analysis [6], and when classified using the PCM classifier yield an overall accuracy of $59.50 \%$. The following input to the classifier was the spectral indices database (12 features; Table 2). In addition to the improvement of the overall classification accuracy (Table 5), the indices input database has resulted in the classification of 7 classes previously unidentified when using the PC input. Entropy measures were calculated for an average of 50 membership vectors per class.

When comparing the indices input (Table 5) and all the spectral-spatial indices (Table 6) for classification, there is a drop in Entropy measures for the majority of the classes, inferring a reduction of uncertainty in determination of class labels to the pixels. Although entropy has reduced, the accuracy assessment of the defuzzified outputs shows a reduced classification accuracy of $62.50 \%$. Significant improvement in classification was obtained for vegetation classes, like Vineyard (Table 6).

Table 6. Spectral-Spatial Indices input database - Entropy and Accuracy Assessment Comparison (1)

\begin{tabular}{|c|c|c|c|c|c|c|c|}
\hline \multirow[t]{2}{*}{$\begin{array}{l}\text { Class } \\
\text { No. }\end{array}$} & \multirow[t]{2}{*}{ Class } & \multicolumn{3}{|c|}{$\begin{array}{l}\text { Indices and Textures } \\
\text { Database ( } 17 \text { features) }\end{array}$} & \multicolumn{3}{|c|}{$\begin{array}{c}\text { Indices and Textures } \\
\text { Database (without MSAVI- } \\
\text { based texture) (16 features) }\end{array}$} \\
\hline & & Entropy & $\mathrm{UA}$ & $\mathrm{PA}$ & Entropy & $\mathrm{UA}$ & $\mathrm{PA}$ \\
\hline 1 & Artificial Turf & 1.146 & 80 & 80 & 1.274 & 100 & 100 \\
\hline 2 & Black Roof & & 37.5 & 75 & & 12.5 & 100 \\
\hline 3 & Building & 0.63 & 60 & 31.58 & 0.44 & 100 & 63.63 \\
\hline 4 & Clay Soil & 1.212 & 80 & 100 & 1.2 & 100 & 100 \\
\hline 5 & Grass & 1.004 & 60 & 85.71 & 1.25 & 90 & 90 \\
\hline 6 & Lawn Tennis Court & 0.64 & 80 & 66.67 & 0.5 & 88.89 & 100 \\
\hline 7 & $\begin{array}{l}\text { Mixed Coniferous } \\
\text { Forest }\end{array}$ & 0.956 & 100 & 71.43 & 1.34 & 100 & 83.33 \\
\hline 8 & $\begin{array}{l}\text { Mixed Deciduous } \\
\text { Forest }\end{array}$ & 1.02 & 80 & 61.54 & 1.35 & 100 & 76.92 \\
\hline 9 & Pasture & 0.966 & 71.43 & 83.34 & 1.25 & 44.44 & 100 \\
\hline 10 & Railway & & 10 & 33.34 & & 25 & 100 \\
\hline 11 & Red Roof & & 20 & 100 & 0.46 & 100 & 91.67 \\
\hline 12 & Red Synthetic Ground & 0.65 & 81.82 & 90 & 0.55 & 42.86 & 100 \\
\hline 13 & Road & & 50 & 15.625 & 0.44 & 88.89 & 24.24 \\
\hline 14 & Roof & & 30 & 27.27 & & 71.43 & 75 \\
\hline 15 & Sand & & 20 & 33.34 & & 14.29 & 100 \\
\hline 16 & Stressed Grass & 1.126 & 80 & 80 & 1.3 & 87.5 & 100 \\
\hline 17 & $\begin{array}{l}\text { Synthetic Sports } \\
\text { Surface }\end{array}$ & 0.65 & 50 & 100 & 0.55 & 87.5 & 100 \\
\hline 18 & Vineyard & 0.94 & 80 & 88.89 & 1.1 & 90.91 & 83.34 \\
\hline 19 & Water & 1.44 & 100 & 76.92 & 1.85 & 90 & 75 \\
\hline \multirow[t]{2}{*}{20} & Yellow Tartan & & 10 & 100 & 0.5 & 33.33 & 100 \\
\hline & $\begin{array}{l}\text { Overall } \\
\text { Classification } \\
\text { Accuracy } \\
\end{array}$ & \multicolumn{3}{|c|}{$62.50 \%$} & \multicolumn{3}{|c|}{$80.50 \%$} \\
\hline
\end{tabular}


Although addition of spatial indices improves the individual classification accuracy for specific classes (like Synthetic Sports Surface, Pastures), the overall classification accuracy drops below the $65 \%$ achieved when using only spectral indices. Therefore, choice of the spatial classes is investigated while using a total of 16 (without MSAVI-based texture) and 15 (without MSAVI-based and Black Roof Entropy textures) while including all spectral indices (Table 2). While using the combination of 16 indices, the highest accuracy (Table 6 ) of $80.50 \%$ was achieved with better individual accuracies and reduced degrees of uncertainty for classification.

Although a few classes were not identified by the Possibilistic $c$-means classifier, their results were measured after defuzzification of the classification output because defuzzification assigns the class label with highest membership value to the pixel.

Table 7. Spectral-Spatial Indices input database - Entropy and Accuracy Assessment Comparison (2)

\begin{tabular}{|c|c|c|c|c|}
\hline \multirow[t]{2}{*}{$\begin{array}{l}\text { Class } \\
\text { No. }\end{array}$} & \multirow[t]{2}{*}{ Class } & \multicolumn{3}{|c|}{$\begin{array}{l}\text { Indices and Textures Database } \\
\text { (without MSAVI-based and Black } \\
\text { Roof Entropy textures) (15 features) }\end{array}$} \\
\hline & & Entropy & $\mathrm{UA}$ & $\mathrm{PA}$ \\
\hline 1 & Artificial Turf & 1.296 & 100 & 100 \\
\hline 2 & Black Roof & & 30 & 100 \\
\hline 3 & Building & 0.399 & 100 & 70.59 \\
\hline 4 & Clay Soil & 1.14 & 100 & 100 \\
\hline 5 & Grass & 1.17 & 80 & 80 \\
\hline 6 & Lawn Tennis Court & 0.46 & 75 & 100 \\
\hline 7 & Mixed Coniferous Forest & 1.18 & 100 & 83.33 \\
\hline 8 & Mixed Deciduous Forest & 1.2 & 90 & 81.82 \\
\hline 9 & Pasture & 1.19 & 70 & 100 \\
\hline 10 & Railway & & 12.5 & 33.33 \\
\hline 11 & Red Roof & 0.44 & 63.64 & 70 \\
\hline 12 & Red Synthetic Ground & 0.52 & 75 & 85.71 \\
\hline 13 & Road & 0.41 & 73.33 & 28.95 \\
\hline 14 & Roof & & 72.73 & 66.67 \\
\hline 15 & Sand & & 0 & 0 \\
\hline 16 & Stressed Grass & 1.16 & 100 & 63.64 \\
\hline 17 & Synthetic Sports Surface & 0.54 & 75 & 100 \\
\hline 18 & Vineyard & 1.1 & 50 & 100 \\
\hline 19 & Water & 1.138 & 100 & 83.33 \\
\hline \multirow[t]{2}{*}{20} & Yellow Tartan & 0.5 & 11.12 & 100 \\
\hline & $\begin{array}{l}\text { Overall Classification } \\
\text { Accuracy }\end{array}$ & \multicolumn{3}{|c|}{$72 \%$} \\
\hline
\end{tabular}

\section{DISCUSSIONS}

The results illustrate that using the spectral-spatial indices do indeed improve the accuracy of the classification. However, a key inference from the results is that not all spatial indices added valuable information to the database. Removal of MSAVI-based texture (Table 6) improved the overall classification accuracy of the dataset. 
This combination of knowledge-based feature selection and extraction for classification improves classification accuracy for specific classes, while intrinsically reducing the dimensionality of the hyperspectral dataset.

The baseline classification follows a traditional dimensionality reduction method performing Principal Component Analysis to reduce the hyperspectral data to its intrinsic dimensionality of 7 PCs. The achieved accuracy of $59.50 \%$ resulted in the least number of classes successfully identified. The usage of spectral indices (Table 2), irrespective of the arising conflicts of classes (Table 3) improves the classification accuracy for the dataset. The knowledge-based choice of spectral information and reduction of dimensionality allows the classifier to identify and classify the pixels with greater accuracy. As spectral information is utilised, vegetation classes (Mixed Coniferous, Deciduous forests, Pastures and Stressed Grass) see an improvement in classification. Marginal improvement in classification of Clay Soil and Artificial Turf classes is seen when using the spectral index. However, at this stage, there are classes like Black Roof, Grass and Synthetic Sports Surface that remain unidentified. The Railway class remains unclassified through all the spectral-spatial indices inputs. It is considered to be a more spatial information based feature, and thus the suggestion (Section 8) to explore Object Oriented classification approaches in future work.

The identification of classes improves when using spectral and spatial features as the input database. Although the overall accuracy has reduced in comparison to spectral indices input, the accuracy of classifying Grass and forest classes is improved. The entropy measure is much reduced in this case, in agreement with better classification results and lower degree of uncertainty while assigning class labels. Identification of which spatial features add most value against dimensionality requires further investigation, thereby formulating the next input database of 12 spectral and 4 spatial indices (excluding the MSAVI-based texture). In comparison with the database of 17 input features (Table 6), entropy measures for classes like Buildings, Clay Soil, Lawn Tennis Court, Red Synthetic Ground and Synthetic Sports Surface is lower than the input database of 17 features. For the same classes, there is also an improvement in classification accuracy (UA). The Road class is identified when reducing the input features from 17 to 16, also with a low entropy and high (UA) accuracy. Some of the classes (Vineyard and Mixed Forest classes) saw an increase in entropy, but also an increase in classification accuracy; conversely the Water class showed an increase in entropy and decrease in classification accuracy. The MSAVI-based texture index formulated from the MSAVI spectral index was initially added to the input database to distinguish between vegetation classes. However, the overall classification accuracy is the best of the many combinations of inputs to the classifier, thereby signifying that value of the remaining texture indices (Table 4). Using the spatial index of Second Moment, derived from Mixed Coniferous Forest based spectral index is considered to provide distinguishable amount of information to identify Grass and Forest classes apart and improve their classification accuracy at the same time. It is noted that only 4 classes could not be identified using PCM and the 16 feature input database, and overall improvement of accuracy is achieved.

In order to test the significance of the remaining 4 spatial indices, various combinations of usage were tested. The only significant result obtained was when using 15 features (excluding MSAVI-based Second Moment and Black Roof-based Entropy texture measures) which achieved an overall classification accuracy of $72 \%$.

\section{CONCLUSIONS}

The results illustrate the applicability of the method of using spectral and spatial indices for classification. The usage of spectral and spatial information to the classifier improves the accuracy, but the input dataset must be evaluated to find the best possible combination of indices database. The authors insist at this stage that every dataset is characteristic in its own unique way, and assessment of knowledge-based dimensionality reduction intrinsically requires an understanding of the specific class that needs to be identified.

For the purpose of future research, possible directions could be:

1. Evaluating the application of Object Oriented classification as it accommodates for both spectral and spatial information.

2. A few of the classes were not classified in all the combinations of inputs for the classifier. Although this has been attributed to the relative smaller spatial distribution of pixels. The classes' contribution to this classification approach could be evaluated by considering a different study area that has a higher distribution of such classes. 
3. The optimal choice of hyperspectral bands is an ongoing domain of research in itself. For specific classes, an automated method of identifying bands could be investigated. Literature encourages the investigation, as the process of determining optimal bands for agricultural crop characteristics is being done by using field-collected biophysical variables [54].

\section{ACKNOWLEDGMENTS}

The author(s) would like to thank Prof Mark Richardson and Cranfield University for providing advice and financial assistance for completion and presentation of this paper at the SPIE Remote Sensing 2016 conference.

\section{REFERENCES}

[1] Qian, S.-E. and Chen, G., "A new nonlinear dimensionality reduction method with application to hyperspectral image analysis," 270-273, IEEE International (2007).

[2] Lillesand, T. M., Kiefer, R. W., and Chipman, J. W., [Remote Sensing and Image Interpretation], John Wiley and Sons (Asia) Pte. Ltd., Singapore, Sanjeev Offset Printers, Delhi, 5th ed.

[3] da Silva, C. R., Centeno, J. A. S., and Aranha, S. R., "Reduction of the dimensionality of hyperspectral data for the classification of agricultural scenes," (2008).

[4] Vane, G. and Goetz, A. F., "Terrestrial imaging spectroscopy," Remote Sensing of Environment 24(1), 1-29 (1988).

[5] Hughes, G., "On the mean accuracy of statistical pattern recognizers," IEEE Transactions on Information Theory 14, 55-63 (Jan 1968).

[6] Kallepalli, A., Kumar, A., and Khoshelham, K., "Entropy based determination of optimal principal components of Airborne Prism EXperiment (APEX) imaging spectrometer data for improved land cover classification," The International Archives of Photogrammetry, Remote Sensing and Spatial Information Sciences 40(8), 781 (2014).

[7] Harsanyi, J. C. and Chang, C.-I., "Hyperspectral image classification and dimensionality reduction: An orthogonal subspace projection approach," Geoscience and Remote Sensing, IEEE Transactions on 32(4), 779-785 (1994).

[8] Keyworth, S., Jarman, M., and Medcalf, K., "Assessing the extent and severity of erosion on the upland organic soils of Scotland using earth observation - A GIFTSS implementation test," tech. rep., Environment Systems Limited (2009).

[9] Kallepalli, A., Spectral and Spatial Indices based Specific Class Identification from Airborne Hyperspectral Data, Master's thesis, Faculty of Geo-information Science and Earth Observation (ITC), University of Twente (2014).

[10] Van Campenhout, J. M., "On the peaking of the Hughes mean recognition accuracy: the resolution of an apparent paradox," Systems, Man and Cybernetics, IEEE Transactions on 8(5), 390-395 (1978).

[11] Jolliffe, I. T., [Principal Component Analysis], Springer, New York (2002).

[12] Rodarmel, C. and Shan, J., "Principal component analysis for hyperspectral image classification," Surveying and Land Information Science 62(2), 115-122 (2002).

[13] Green, A. A., Berman, M., Switzer, P., and Craig, M. D., "A transformation for ordering multispectral data in terms of image quality with implications for noise removal," IEEE Transactions on Geoscience and Remote Sensing 26, 65-74 (Jan 1988).

[14] Plaza, A., Martinez, P., Plaza, J., and Perez, R., "Dimensionality reduction and classification of hyperspectral image data using sequences of extended morphological transformations," IEEE Transactions on Geoscience and Remote Sensing 43, 466-479 (Mar. 2005).

[15] Gillespie, A., Smith, M., Adams, J., Willis, S., Fischer, A., and Sabol, D., "Interpretation of residual images: spectral mixture analysis of AVIRIS images, Owens Valley, California," in [Proceedings of the 2nd airborne visible/infrared imaging spectrometer (AVIRIS) workshop], 243-270, NASA Jet Propulsion Laboratory Pasadena, CA (1990).

[16] Jain, A. and Zongker, D., "Feature selection: Evaluation, application, and small sample performance," Pattern Analysis and Machine Intelligence, IEEE Transactions on 19(2), 153-158 (1997). 
[17] Jensen, J. R., "Biophysical remote sensing," Annals of the Association of American Geographers 73(1), 111-132 (1983).

[18] Haralick, R. M., Shanmugam, K., et al., "Textural features for image classification," IEEE Transactions on Systems, Man, and Cybernetics (6), 610-621 (1973).

[19] Estes, J., Hajic, E., and L.R., T., "Fundamentals of image analysis: Analysis of visible and thermal infrared data.," in [Manual of Remote Sensing], Colwell, R., ed., 1, 987-1124, American Society of Photogrammetry, 2 ed. (1983).

[20] Wolf, P. R. and Dewitt, B. A., [Elements of Photogrammetry: with applications in GIS], vol. 3, McGraw-Hill New York (2000).

[21] Jordan, C. F., "Derivation of leaf-area index from quality of light on the forest floor," Ecology 50(4), 663-666 (1969).

[22] Liu, G.-R., Liang, C.-K., Kuo, T.-H., Lin, T.-H., and Huang, S., "Comparison of the NDVI, ARVI and AFRI Vegetation Index, along with their relations with the AOD using SPOT 4 vegetation data," Terrestrial Atmospheric and Oceanic Sciences 15(1), 15-32 (2004).

[23] Rouse, Jr., J. W., Haas, R. H., Schell, J. A., and Deering, D. W., "Monitoring Vegetation Systems in the Great Plains with ERTS," NASA Special Publication 351, 309 (1974).

[24] Huete, A. R., "A soil-adjusted vegetation index (SAVI)," Remote sensing of environment 25(3), 295-309 (1988).

[25] Carter, G. A., Cibula, W. G., and Dell, T. R., "Spectral reflectance characteristics and digital imagery of a pine needle blight in the south-eastern United States," Canadian Journal of Forest Research 26(3), 402-407 (1996).

[26] Vogelmann, J., Rock, B., and Moss, D., "Red edge spectral measurements from sugar maple leaves," Remote Sensing 14(8), 1563-1575 (1993).

[27] Gitelson, A. A. and Merzlyak, M. N., "Remote estimation of chlorophyll content in higher plant leaves," International Journal of Remote Sensing 18(12), 2691-2697 (1997).

[28] Haboudane, D., Miller, J. R., Pattey, E., Zarco-Tejada, P. J., and Strachan, I. B., "Hyperspectral vegetation indices and novel algorithms for predicting green LAI of crop canopies: Modeling and validation in the context of precision agriculture," Remote Sensing of Environment 90(3), 337-352 (2004).

[29] Broge, N. H. and Leblanc, E., "Comparing prediction power and stability of broadband and hyperspectral vegetation indices for estimation of green leaf area index and canopy chlorophyll density," Remote sensing of environment 76(2), 156-172 (2001).

[30] Daughtry, C., Walthall, C., Kim, M., De Colstoun, E. B., and McMurtrey, J., "Estimating corn leaf chlorophyll concentration from leaf and canopy reflectance," Remote sensing of Environment 74(2), 229-239 (2000).

[31] Qi, J., Chehbouni, A., Huete, A., Kerr, Y., and Sorooshian, S., "A modified soil adjusted vegetation index," Remote sensing of environment 48(2), 119-126 (1994).

[32] Elvidge, C. D. and Chen, Z., "Comparison of broad-band and narrow-band red and near-infrared vegetation indices," Remote sensing of environment 54(1), 38-48 (1995).

[33] Tucker, C. J., "Red and photographic infrared linear combinations for monitoring vegetation," Remote sensing of Environment 8(2), 127-150 (1979).

[34] Richardson, A. J. and Wiegand, C., "Distinguishing vegetation from soil background information [by gray mapping of Landsat MSS data]," (1977).

[35] Kim, M. S., [The Use of Narrow Spectral Bands for Improving Remote Sensing Estimations of Fractionally Absorbed Photosynthetically Active Radiation (fapar)] (1994).

[36] Zarco-Tejada, P. J., Miller, J. R., Noland, T. L., Mohammed, G. H., and Sampson, P. H., "Scaling-up and model inversion methods with narrowband optical indices for chlorophyll content estimation in closed forest canopies with hyperspectral data," IEEE Transactions on Geoscience and Remote Sensing 39(7), 1491-1507 (2001).

[37] Peñuelas, J., Gamon, J., Fredeen, A., Merino, J., and Field, C., "Reflectance indices associated with physiological changes in nitrogen-and water-limited sunflower leaves," Remote Sensing of Environment 48(2), 135-146 (1994). 
[38] Zarco-Tejada, P. J., Miller, J., Morales, A., Berjón, A., and Agüera, J., "Hyperspectral indices and model simulation for chlorophyll estimation in open-canopy tree crops," Remote sensing of environment 90(4), 463-476 (2004).

[39] Zarco-Tejada, P. J., Berjón, A., López-Lozano, R., Miller, J., Martín, P., Cachorro, V., González, M., and De Frutos, A., "Assessing vineyard condition with hyperspectral indices: Leaf and canopy reflectance simulation in a row-structured discontinuous canopy," Remote Sensing of Environment 99(3), 271-287 (2005).

[40] Hall, A., Lamb, D., Holzapfel, B., and Louis, J., "Optical remote sensing applications in viticulture-a review," Australian Journal of Grape and Wine Research 8(1), 36-47 (2002).

[41] Gamon, J., Penuelas, J., and Field, C., "A narrow-waveband spectral index that tracks diurnal changes in photosynthetic efficiency," Remote Sensing of environment 41(1), 35-44 (1992).

[42] Gitelson, A. A., Zur, Y., Chivkunova, O. B., and Merzlyak, M. N., "Assessing carotenoid content in plant leaves with reflectance spectroscopy," Photochemistry and photobiology 75(3), 272-281 (2002).

[43] Zha, Y., Gao, J., and Ni, S., "Use of normalized difference built-up index in automatically mapping urban areas from TM imagery," International Journal of Remote Sensing 24(3), 583-594 (2003).

[44] Gao, B.-C., "NDWI-A normalized difference water index for remote sensing of vegetation liquid water from space," Remote sensing of environment 58(3), 257-266 (1996).

[45] Herold, M., Couclelis, H., and Clarke, K. C., "The role of spatial metrics in the analysis and modeling of urban land use change," Computers, Environment and Urban Systems 29, 369-399 (July 2005).

[46] Clausi, D. A., "An analysis of co-occurrence texture statistics as a function of grey level quantization," Canadian Journal of remote sensing 28(1), 45-62 (2002).

[47] Datt, B., McVicar, T., Van Niel, T., Jupp, D., and Pearlman, J., "Preprocessing EO-1 Hyperion hyperspectral data to support the application of agricultural indexes," IEEE Transactions on Geoscience and Remote Sensing 41, 1246-1259 (June 2003).

[48] "Free Data Cubes - APEX - Airborne Prism EXperiment." http://www.apex-esa.org/content/ free-data-cubes. [Online; accessed 2016-08-06].

[49] Schaepman, M. E., Jehle, M., Hueni, A., D’Odorico, P., Damm, A., Weyermann, J., Schneider, F. D., Laurent, V., Popp, C., Seidel, F. C., et al., "Advanced radiometry measurements and Earth science applications with the Airborne Prism EXperiment (APEX)," Remote Sensing of Environment 158, 207-219 (2015).

[50] "SwissTopo Web Portal." http://map.geo . admin . ch/?topic=ech\&lang=en\&X=257116 . 37\&Y=664823.41\& zoom=6\&bgLayer=ch . swisstopo . swissimage. [Online; accessed 2016-08-08].

[51] Cho, M. A. and Skidmore, A. K., "A new technique for extracting the red edge position from hyperspectral data: The linear extrapolation method," Remote sensing of environment 101(2), 181-193 (2006).

[52] Foody, G. M., "Sub-pixel methods in remote sensing," in [Remote sensing image analysis: Including the spatial domain], 37-49, Springer (2004).

[53] Krishnapuram, R. and Keller, J. M., "A Possibilistic approach to clustering," IEEE Transactions on Fuzzy Systems 1(2), 98-110 (1993).

[54] Thenkabail, P. S., Smith, R. B., and De Pauw, E., "Evaluation of narrowband and broadband vegetation indices for determining optimal hyperspectral wavebands for agricultural crop characterization," Photogrammetric Engineering and Remote Sensing 68(6), 607-622 (2002).

[55] Thenkabail, P. S., Smith, R. B., and De Pauw, E., "Hyperspectral vegetation indices and their relationships with agricultural crop characteristics," Remote Sensing of Environment 71(2), 158-182 (2000).

[56] Penuelas, J., Filella, I., Biel, C., Serrano, L., and Save, R., "The reflectance at the 950-970nm region as an indicator of plant water status," International Journal of Remote Sensing 14(10), 1887-1905 (1993). 